\title{
LA NOCIÓN DE LOGISMOÍ EN EVAGRIO PÓNTICO: EL CORRELATO COGNITIVO DE LAS PASIONES ENFERMAS
}

\author{
THE NOTION OF LOGISMOÍ IN EVAGRIUS \\ PONTICUS: THE COGNITIVE CORRELATE OF \\ SICK PASSIONS
}

\author{
Santiago HeRnÁn VAZQUEZ*
}

UNCUYO-CONICET

\begin{abstract}
ResUmen: El presente trabajo se propone profundizar en una noción característica de la obra del filósofo tardoantiguo, Evagrio Póntico. Dicha noción es la de logismoí. Las distintas modulaciones y sentidos con que Evagrio se refiere a este tópico, justifica la necesidad de acercarse a éste a fin de lograr una conceptualización coherente del mismo que contemple todos sus sentidos. Se trata principalmente de dilucidar si estamos frente a una realidad psíquica y/o frente a lo que nuestro autor considera una sugestión preternatural. Creemos que comprender estos como el correlato cognitivo de las pasiones, enfermas a raíz de la ignorancia de sí, constituye la clave de bóveda para acceder a una conceptualización coherente.
\end{abstract}

Palabras clave: Logismoí, Pasiones, Enfermedad, Demonios

"Licenciado en Psicología, Doctor en Filosofía. Email: santiagohernanvazquez@gmail. com. Domicilio: Almirante Brown 2900, Loteo Los Olmos casa 32, Vistalba, Luján de Cuyo (Mendoza, Argentina) 
АвsтRACт: The present work intends to deepening in a characteristic notion of the the writings of the philosopher of the Late Antiquity, Evagrio Póntico. This is, the notion of logismoi. The different modulations and meanings, with which Evagrio refers to this topic, justifies the need to approach it in order to achieve a coherent conceptualization that contemplates all his senses. We will try to elucidating whether we are facing a psychic reality and/or -what our author considers- a preternatural suggestion. We believe that the understanding of these logismo $i$ as the cognitive correlate of the passions, which are diseased as a result of self-ignorance, constitutes the vault key to access a coherent conceptualization.

Keywords: Logismoí, Passions, Disease, Demons

\section{Introducción}

Recogiendo una rica herencia clásica que va de Platón a la medicina hipocrático-galénica pasando por el estoicismo y la teología patrística (principalmente la de la Escuela de Alejandría), Evagrio Póntico, el monje filósofo del siglo IV, elaborará una compleja noción de enfermedad del alma que redundará en un enfoque psicoespiritual de notable precisión en el que se destaca una noción muy característica de su obra y muy cara para el pensamiento cristiano posterior: la de logismoí en tanto categoría por la que se tipifica la actividad cognitiva que emerge de las pasiones enfermas. En otros lugares nos hemos ocupado de profundizar en aquella compleja noción de enfermedad del alma ${ }^{1}$, a la luz de la cual consideramos que debe entenderse la noción de logismoí, de acuerdo a nuestra interpretación de la concepción evagriana. Consignemos aquí que la conclusión a la que arribamos en la etapa previa a este estudio es que la enfermedad propia del alma para Evagrio Póntico es la ignorancia de sí. El nous caído (tal cosa es el hombre para nuestro autor) ignora, a consecuencia de haberse desprendido de la unidad con Dios, quién es, ignora su condición espiritual y su vocación de unicidad con el Creador. Tal ignorancia engendra un amor de sí parà phýsin-llamado por Evagrio filautía $(\phi(\lambda \alpha v \tau \imath \alpha)$ - que posee como objeto el propio cuerpo. Dicho amor genera, a su vez, una actividad de la parte pasional del alma, también parà phýsin en tanto busca la satisfacción de ese cuerpo, que posee un correlato cognitivo rayano en lo patológico y que Evagrio denomina logismoi. Este es, en apretada síntesis, lo que podría llamarse el cuadro etiológico completo de la concepción evagriana de enfermedad del alma.

1 Cfr. Vazquez, 2017: 4-17; 2018. 
A la luz de tal concepción procuraremos acercarnos al concepto de logismoí. Como sucede frecuentemente con la obra de Evagrio, se trata de un tópico disperso por su obra, tratado por aproximaciones sucesivas, con distintas modulaciones conceptuales y, por lo mismo, de compleja sistematización ${ }^{2}$. Nuestro objetivo será tratar de identificar y diferenciar en la obra evagriana todas las realidades psicoespirituales que nuestro autor quiere designar con tal concepto y buscar en el vínculo causal que los logismoí tienen con las pasiones y en el lugar que ocupan dentro del dinamismo "patológico" de la ignorancia, las ideas que unifiquen las diversas acepciones y sentidos que tiene el término en la obra evagriana.

\section{Logismoí: parte de la estructura del psiquismo en tanto nous caído}

Indica el kephálaion 57 de Capitulos de los discípulos de Evagrio3: "Es necesario que el monje desprecie la glotonería, la avaricia, la vanagloria, el amor del placer y la filautía, que es la madre de todos, y también al que es enemigo del alma, es decir, la carne, porque allí están los logismoi fundamentales" (57).

Esta es la primera parte del kephálaion. La filautía es aquí $\mu$ ๆ $\tau \eta \rho:$ madre, fuente, origen. Ella es amor al enemigo del alma y, en cuanto tal, fuente de

\footnotetext{
2 Acerca de esta condición de la obra de Evagrio, indica Julia Konstantinovsky al referirse al tópico de la contemplación natural: "No es tarea fácil sistematizar la doctrina de la contemplación natural de Evagrio. Como generalmente sucede con su obra, las ideas de Evagrio acerca de los grados y substancias de contemplación están dispersos a través del su corpus entero por lo que se deben tener en cuenta los diferentes contextos." (Konstantinovsky, 2009: 48. El subrayado es nuestro)

3 Aunque no se puede decir que esta obra fue escrita directamente por Evagrio, no quedan dudas acerca de lo que los especialistas llaman "autoría derivativa" de tal obra. Se trata, en efecto, de una colección de dichos de Evagrio compilados por sus discípulos y que presentan con relativa originalidad los grandes tópicos del pensamiento del Póntico entregándonos, como indican los editores, las últimas elaboraciones de éste. Es por ello que Sources Chrétiennes incluye y edita directamente esta obra dentro de los escritos de autoría evagriana. Cfr. Géhin, 2007: 19-89; Kalvesmaki, 2017: en línea; Larchet, 2007: en línea. En un estudio, previo a la edición de Sources Chrétiennes, de los manuscritos sobre los que se hizo dicha edición, Joseph Paramelle indicaba lo siguiente: "En su conjunto, estos capítulos nos conservan el eco bien reconocible de la doctrina de Evagrio, tal como ella se ha transmitido, sin duda a partir de la lectura de sus obras, seguramente gracias al recuerdo de su enseńanza oral, tal como ella ha evolucionado en un medio que sigue siendo bastante fiel a su recuerdo para continuar, en despecho de la sospecha precoz y de los anatemas del 553, apelando a su nombre" (J. Paramelle, 1978: 111-12).
} 
la que emergen los logismoí . Éstos son, en la elaborada psicología evagriana, la actividad cognitiva característica del alma enferma o apasionada, o, mejor, la lógica misma de las pasiones como indica Forthomme $e^{5}$ Este mismo autor señala algo en consonancia con nuestro desarrollo: "Los logismoí son parte de la estructura del psiquismo en la medida en que éste es afectado por el alejamiento ontológico de la unidad" (Forthomme, 2000: 501). Esto explica que digamos que los logismoí designan la actividad cognitiva propia del alma enferma. El alma enferma, en efecto, es en la concepción evagriana el nous que ha caído del estado de unidad, o que padece el "alejamiento ontológico de la unidad" como aquí indica Forthomme ${ }^{6}$. Porque ha caído de la unidad, el nous ignora qué y quién es el, se concibe a sí mismo erróneamente (como cuerpo) y ama eso que él cree que es. Esto desorbita su parte pasional que comienza a buscar la satisfacción corporal y engendra una actividad cognitiva que Evagrio llama logismoí. De modo que, estos logismoí son, efectivamente, "parte de la estructura del psiquismo" en tanto este psiquismo refiere el nous que se ha separado o alejado de la unidad.

Es por esto que no es conveniente traducir el término logismoí. Este vocablo tiene siempre en Evagrio un sentido peyorativo que no sería bien expresado en la traducción correspondiente de "pensamientos". Pero sigamos indagando los

4 Para ver los posibles antecedentes históricos de este concepto evagriano de logismoí se puede consultar: Guillaumont, 1971: 63-84; Daniélou, 1957: 187; Pesthy, 2003: 1017-1022.

Aunque ciertamente puedan espigarse en las tradiciones antiguas y tardoantiguas que estos autores consideran, nociones que podría haber resultado la fuente del concepto evagriano, lo cierto es que "la 'fuente' más relevante de Evagrio en su teoría de los ocho logismoí no es necesario buscarla en autores anteriores ya que no se trata de conclusiones teóricas conseguidas luego de un proceso deductivo y a partir de antecedentes literarios sino más bien de la sistematización de la observación psicológica y de la propia experiencia conseguidas en sus años de vida monástica en el desierto egipcio como monje y como maestro de monjes." (Peretó Rivas, 2014: 88).

5 Cfr. Forthomme, 2000: 500.

6 Para una comprensión más completa de nuestra interpretación de la concepción evagriana de enfermedad del alma, remitimos a nuestra ya citada contribución "La enfermedad del alma en el filósofo tardo antiguo Evagrio Póntico: entre ignorancia y filautía" (Vazquez, 2018). Consignemos, no obstante, dos textos evagrianos claves en el marco de dicha interpretación y útiles para visualizar algunos de los fundamentos textuales de nuestras afirmaciones: "No es la unidad la que, por sí misma, se pone en movimiento; sino que ella es puesta en movimiento por la receptividad del nous, el cual por su negligencia, desvía de ella su rostro y, por el hecho de ser privado de ella, engendra la ignorancia” (Kephálaia Gnóstica I, 49).

"La riqueza del alma es la ciencia, y su pobreza la ignorancia; pero si la ignorancia es privación de ciencia, la riqueza es anterior a la pobreza, y la salud del alma a su enfermedad." (Kephálaia Gnóstica II, 8). 
textos evagrianos a fin de ir probando todas nuestras afirmaciones e ir delineando nuestra interpretación del concepto.

En lo que sigue del texto de aquel kephálaion de Capitulos de los discipulos de Evagrio, los logismoi reciben una importante caracterización:

Al principio ellos abordan el alma con dulzura y una gran fuerza persuasiva, como si ellos tuvieran piedad del cuerpo y le prometieran alguna comodidad, pero al fin, ellos se lanzan sobre ella descaradamente, entonces ella no puede deshacerse de ellos, porque ella ha acogido las pasiones fundamentales capaces de engendrarlos (57).

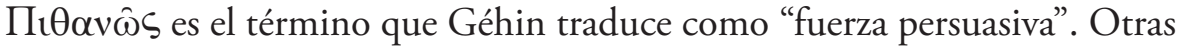
traducciones que el término admite pueden ser las de "argumentos convincentes" o "argumentos verosímiles". Estos pensamientos enraizados en la filautía operan mediante el lenguaje y elaboran argumentos con apariencia de verdad, cuyo único fin es asegurar el bienestar del cuerpo sin que esto parezca ir en detrimento del alma. Por ello se afirma que la disuaden razonando, argumentando, como si ellos ofrecieran algún acuerdo, un trato (tal otra posible traducción de

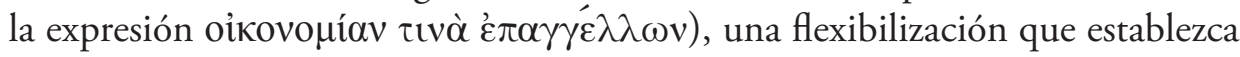
una avenencia entre el deber ascético y el cuidado del cuerpo. Sin violentar al alma que es abordada con dulzura, con suavidad ( $\pi \rho \alpha \hat{\alpha} \omega \varsigma)$, este ofrecimiento busca garantizar la satisfacción y la comodidad del cuerpo. De esta manera las pasiones se profundizan y los logismoi que de ellas nacen hostigan con mayor fuerza al alma cual "flechas inteligibles" que vienen de la parte pasional del alma llegando de este modo a "horadar la libertad" (Peretó Rivas, 2011: 160), pues el alma ya no puede "deshacerse de ellos". Acogiéndolos ha dado mayor fuerza a las pasiones que se van adueñando del alma.

7 Cfr. Kephálaia Gnóstica VI, 53. 
Con esto se introduce ya una caracterización bastante precisa de los llamados logismoí, los cuales constituyen una especie de eslabón final en la consideración evagriana de la enfermedad del alma.

\section{La enfermedad del alma y las pasiones como fuente}

Dependientes de la filautía, los logismoí se especifican por el hecho de constituir lo que con Tobon podemos llamar la "actividad cognitiva característica" del alma enferma ${ }^{8}$. En otro lugar la misma autora los llama "hábitos de pensamiento asociados con 'el viejo yo"' paulino (Tobon, 2011: 767). Las dos definiciones son precisas. En efecto, este viejo yo u hombre viejo paulino designa en Evagrio al alma enferma de ignorancia que se cura -despojándose de ese hombre viejocuando ve su propia luz 9 . Los hábitos de pensamiento o la actividad cognitiva característica de este hombre viejo es la que surge, la que emerge, de un alma signada por la ignorancia y su consecuente filautía.

En una de sus cartas, nuestro autor indica reveladoramente que, de los pensamientos tentadores que nos asaltan, unos proceden de la naturaleza, no son malos en sí mismos pero aquí "la perfidia del maligno" puede "causar la muerte en vosotros por medio de cosas buenas". Pero los otros, los logismoí propiamente dichos, tienen lugar debido a "la enfermedad $\left(\alpha \sigma \theta \varepsilon v \varepsilon i \alpha \varsigma^{10}\right)$ de nuestra

8 Cfr. Tobon, 2010: 7.

9 "Cuando el intelecto se haya despojado del hombre viejo y se haya revestido de aquel que nace de la gracia, entonces es su propio estado el que verá al momento de la oración, similar al zafiro o al color del cielo; es el estado que la Escritura nombre el lugar de Dios, que ha sido visto por los Ancianos sobre el monte Sinaî" (Sobre los Pensamientos 39).

10 En la utilización del término ỏ $\sigma \theta^{\prime} \varepsilon v \varepsilon \iota \alpha$ en tanto enfermedad, nuestro autor parece estar articulando una tradición antropológica cristiana que se enraíza en la Sagrada Escritura, y más precisamente en la versión griega de los LXX del libro sagrado. Juan Carlos Alby se ha ocupado detenidamente del análisis y el rastreo de este término en la Sagrada Escritura y en la antropología cristiana primitiva. Aunque este autor no se ocupe de Evagrio Póntico, claramente la conclusión a la que arriba se aplica también a nuestro filósofo del desierto. En efecto, Alby indica que "El significado primario de asthéneia tanto en el Antiguo como en el Nuevo Testamento es el de enfermedad corporal. No obstante, en la medida en que la antropología cristiana avanzó hacia formulaciones más elaboradas, la concepción de hombre sostenida por los primeros cristianos como un ser en relación con lo divino a través de su dimensión espiritual y con el cosmos creado por Dios, produjo una expansión de su campo semántico generándose otros indicadores de la debilidad connotada por el término, tales como la flaqueza en la fe o la que deviene de las injurias y persecuciones. El horizonte de la enfermedad se amplió más allá de la esfera corporal hacia aspectos propios de la experiencia 
propia voluntad" o de nuestro poder de elegir, que a esto remite el término $\pi \rho \circ \alpha i \rho \varepsilon \sigma \varepsilon \omega \varsigma$ usado aquí por nuestro autor. Éstos "se producen por la irascibilidad $(\theta v \mu \circ v)$ y la concupiscencia ( $\varepsilon \pi \imath \theta v \mu \dot{\mu} \alpha \varsigma)$ " (Carta 55, 2). Con ello nuestro autor está indicando que los logismoi proceden de la parte pasional y se imponen a nuestra voluntad sin que ella pueda hacer nada frente a su surgimiento. Surgen, emergen, de la ỏ $\sigma \theta^{\prime} \varepsilon v \varepsilon \imath \alpha$ de nuestra alma y en virtud de ello somos incapaces de elegir experimentarlos o no: "Que todos estos pensamientos perturben el alma o no la perturben, esto no depende de nosotros; pero que ellos permanezcan o no permanezcan, que ellos desencadenen las pasiones o no las desencadenen, he aquí lo que depende de nosotros" (Tratado Práctico 6).

Los logismoi mueven las pasiones pero, a su vez, son formados a partir de ellas y, en rigor, son casi indiscernibles de ellas ${ }^{11}$. Digamos que son una especie de correlato lógico-verbal-imaginativo de las pasiones, o, como quiere Forthomme, la estructura lógica de éstas ${ }^{12}$. En efecto, el término logismoí designa en Evagrio razonamientos, representaciones, sugestiones verbales interiores, que proceden de las pasiones. Bunge indica al respecto: "antes de volverse acción, las pasiones escondidas en el corazón se manifiestan concretamente en pensamientos (logismoi)" (Bunge, 1989: 35). Que procedan de las pasiones y que por tanto sean casi identificables con ellas (hasta tal punto de que nuestro autor a veces se refiere indistintamente a unos y a otras $\left.{ }^{13}\right)$, es algo que Evagrio afirma en muchos

religiosa." (Alby, 2011: 11-26, 24). Evagrio resulta un ejemplo eminente de lo que refiere Alby. En su obra puede rastrearse, en efecto, esta doble significación del término ỏ $\sigma \theta^{\prime} \varepsilon v \varepsilon t \alpha$. Como enfermedad corporal aparece, por ejemplo, en tres capítulos del Tratado Práctico: en el 40 hablando de la tentación que recae sobre alguien que está físicamente enfermo ( $\left.\alpha \sigma \theta \varepsilon v o \hat{v} \tau \alpha \varsigma_{)}\right)$, en el 82 refiriéndose a posibles miembros del cuerpo en estado mórbido ( $\alpha \sigma \theta \varepsilon v o v v \tau \omega \nu \mu \varepsilon \lambda \omega \hat{\omega} v)$ y en el 91 hablando de la obra del servicio de los enfermos ( $\alpha \sigma \theta \dot{\varepsilon} v o \hat{\sigma} \sigma)$ que los monjes podían eventualmente llevar a cabo. Designando enfermedades espirituales o del alma aparece, por ejemplo, en el capítulo 13 de Ocho espíritus de la maldad. Por lo demás en Escolios a los Proverbios (310) Evagrio aplica efectivamente el término $\alpha_{\alpha} \sigma \dot{\varepsilon} v \varepsilon \varepsilon \alpha$ al intelecto caído, subrayando que esta enfermedad, este estado de debilidad, le es

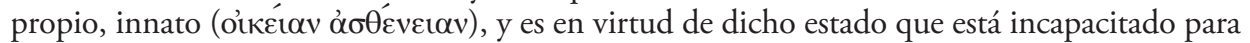
la contemplación, es decir, se halla en una condición parà phýsin, teniendo en cuenta lo que afirma nuestro autor en el capítulo 86 del Tratado Práctico respecto a la contemplación como la actividad katà phýsin del logistikón.

11 “Evagrio utiliza de modo casi indiferente los términos 'demonio', 'pasión' y 'pensamiento' para designar la misma realidad, aun cuando naturalmente las distingue muy bien” (Bunge, 1989: 79-80).

12 Cfr. Forthomme, 2000: 500. Evagrio se refiere, en efecto, a "los pensamientos [propios] de una pasión" (Sobre los pensamientos 34).

13 Por ejemplo, en el Tratado Práctico caracteriza por separado a cada uno de los ocho logismoí y al llegar a la cólera -uno de los ocho- habla de ella como pasión: "La cólera es una 
lugares en los que da a entender de modo explícito que las pasiones enfermas son la matriz de los logismoí:

La pasión está subyacente en el alma, y ella es el origen del logismós

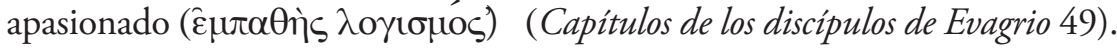

Es en efecto a partir de esas pasiones que se forman poco a poco todos los logismoí demoníacos que precipitan al intelecto 'en la ruina y la perdición' (1 Tim. 6, 9). (Sobre los pensamientos 3)

Todos los logismoi impuros que persisten en nosotros a causa de las pasiones hacen descender el intelecto 'a la ruina y a la perdición' (1 Tim 6, 9). (Sobre los pensamientos 22)

Es cuando el nous se aproxima a los inteligibles, cuando no se une más al logismós que viene de la parte apasionada del alma. (Kephálaia Gnóstica VI, 55)

No son todos los logismoi los que le impiden [al nous] la ciencia de Dios, sino aquellos que lo acosan desde el thymos y desde la epithymia y que son contra natura. (Kephálaia Gnóstica VI, 83)

No te alegre el vino, ni te deleiten las carnes, para que no engordes tu

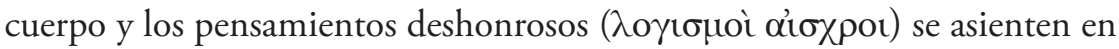
ti. (A los monjes 38)

El que adorna sus vestidos y harta su estómago, alimenta pensamientos

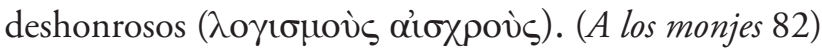

\section{Los logismoí y su carácter imaginativo y lógico-verbal}

El Póntico tipifica minuciosamente la actividad lógico-verbal-imaginativa que se constituye en una especie de correlato cognitivo de la actividad pasional del alma enferma. Categoriza toda esta actividad en lo que él llama ocho

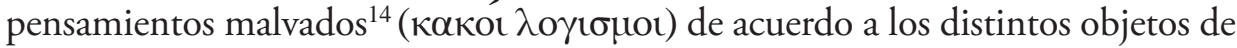
satisfacción que las pasiones persiguen desordenadamente (el dinero, el alimento,

pasión muy rápida. Se dice, en efecto, que ella es un hervor de la parte irascible" (11).

14 Los ocho, de acuerdo al orden del Tratado Práctico, son: gula, fornicación, avaricia, tristeza, cólera, acedia, vanagloria y orgullo. 
los cuerpos, la huida de situaciones dolorosas, la autoexaltación), indica que estos ocho "comprenden todos los pensamientos" (Tratado Práctico 6), y describe e identifica las sugestiones concretas que a modo de lenguaje interior tienen lugar en el pensamiento cual "flechas inteligibles" que son disparadas desde la parte pasional (Kephálaia Gnóstica VI, 53).

Esta condición de correlato cognitivo de las pasiones que caracteriza a los logismoí, y su carácter racional y/o imaginativo, se observa claramente cuando nos detenemos en los ejemplos de logismoí concretos que Evagrio consigna principalmente en su libro Antirrhético, o en algunos de los ejemplos y precisiones que da, principalmente, en su tratado Sobre los Pensamientos. En la primera de estas obras nuestro autor se encarga de identificar minuciosamente las sugestiones ( $\pi \rho \circ \phi \alpha ́ \alpha \sigma \varepsilon \sigma \mathrm{v} v$ es el término, traducido como sugestiones por Guillaumont y Géhin, que usa nuestro autor para referirse a los logismoi en el tratado Sobre los Pensamientos [5]) concretas que pueden surgir de las distintas pasiones, muchas veces mediante la mediación preternatural de los demonios los cuales refuerzan con palabras el movimiento pasional. En un momento volveremos sobre este asunto del posible rol de los demonios en la dinámica de los logismoí.

En la segunda de aquellas obras (Sobre los Pensamientos), el Póntico se centra en el carácter imaginativo que pueden tener estos logismoí. Es decir, el término logismoí designa allí, no solo una actividad racional al servicio de las pasiones, sino también una imaginativa que surge de la misma fuente y busca un mismo fin. Veamos primero esto último, para centrarnos luego en la dimensión más racional que pueden tener los logismoí.

Es, principalmente, en el capítulo 22 del tratado Sobre los Pensamientos, donde Evagrio se referirá con singular claridad a los logismoí en tanto representaciones imaginativas engendradas por las pasiones y, a la vez, movilizadoras de éstas:

Todos los pensamientos impuros que persisten en nosotros a causa de las pasiones hacen descender el intelecto 'a la ruina y a la perdición' (1 Tim. 6 , 9). Porque así como la representación del pan persiste en el hambriento a causa del hambre y la representación del agua persiste en el sediento a causa de la sed, así las representaciones de las riquezas y de los bienes persisten a causa de la codicia, y las representaciones de los alimentos y de los pensamientos vergonzosos que engendran los alimentos persisten a causa de las pasiones. 
Evagrio no identifica los logismoí con las representaciones, pero sí entiende que las representaciones pueden transformarse en logismoi cuando se vuelven apasionadas. Esto es, en efecto, lo que afirma en Capitulos de los discípulos de Evagrio: "El logismós [es] la representación apasionada" (65). Al utilizar el término vơ $\mu \alpha$-que aquí traducimos, siguiendo la lección de Géhin y Guillaumont, como "representación" - para designar primariamente la imagen provocada por la percepción de un objeto sensible, Evagrio está articulando libremente una tradición aristotélico-estoica acerca del proceso de conocimiento ${ }^{15}$. Es decir, se está refiriendo a una instancia propia de la actividad cognoscitiva humana ${ }^{16}$ :

15 Sin duda, se abren aquí una serie de interrogantes. Por ejemplo, en qué sentido Evagrio es receptor de una tradición para la que el término nóema se vincula más al "concepto" que a la "imagen". También si este que lo vincula a la imagen es el único sentido en que el término nóema se encuentra en Evagrio. Géhin y Guillaumont responden estos interrogantes: "Una noción fundamental es expresada por la palabra nóema que, tomada de Aristóteles, aparece 47 veces en este tratado [Sobre los Pensamientos] y que nosotros hemos traducido, después de muchas vacilaciones, por 'representación'. Lo que Evagrio llama nóema para designar la imagen provocada por la percepción de un objeto sensible corresponde exactamente a lo que los estoicos denominaban fantasía, término que se traduce habitualmente por 'representación' [...] Se puede preguntar por qué al término estoico fantasía Evagrio ha preferido la palabra aristotélica nóema. De hecho, en virtud del principio de que todo conocimiento es de origen sensible, el nóema aristotélico tiene por origen la imagen producida por la percepción de un objeto sensible, imagen llamada habitualmente $\phi \alpha ́ v \tau \alpha \sigma \mu \alpha$; pero el nóema es distinto de esta imagen porque, recibido por el intelecto, es elaborado por él, en cierto modo 'conceptualizado', de donde el sentido de 'concepto' que puede recibir habitualmente la palabra (cf. Del Alma III $8431 \mathrm{~b}-436 \mathrm{a}$ ). Se puede pensar que es esta relación estrecha que tiene la imagen con el intelecto lo que ha determinado a Evagrio a designarla por el término nóema, con preferencia al término estoico fantasía" (Géhin, Guillaumont, C. y Guillaumont, A., 1998: 24-25).

El sentido del término nóema que nosotros venimos subrayando y a partir del cual Evagrio trata el tópico de los logismoí, es, entonces, el de representación imaginativa. Sin embargo, indiquemos que el término nóema también asume en otros lugares de la obra evagriana el sentido, quizá más fiel al aristotélico, de representación no imaginativa: "Entre las represen-

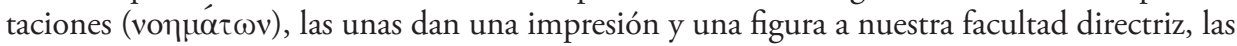
otras suministran solamente un conocimiento, sin imponer al intelecto ni huella ni figura. Así el versículo 'Al comienzo era el Verbo y el Verbo estaba junto a Dios' deposita en el corazón una representación $\left(v_{0} \eta \dot{\mu} \alpha\right)$, sin imponerle una figura o una huella" (Sobre los pensamientos 41); "A través del oído [la mente] capta las representaciones que imprimen una forma o no imprimen una, porque una palabra (puede) significar tanto objetos sensoriales como objetos contemplativos" (Skemmata 17).

Para ver con detenimiento este asunto remitimos a los puntos II y III, de la citada introducción de Géhin y Guillaumont al tratado Sobre los Pensamientos.

16 Por cierto, los vón $\mu \alpha \tau \alpha$ pueden también ser aportados por la memoria que guarda los productos de experiencias perceptivas y cognoscitivas pasadas. Acerca de esto se puede ver: Guillaumont, 2009: 284; Peretó Rivas, 2014: 284-285. 
Es necesario comenzar por decir cómo el intelecto por naturaleza recibe las representaciones de todos los objetos sensibles y una huella conforme a ellos por intermedio del instrumento que es nuestro cuerpo. Tal como sea la forma del objeto, tal será necesariamente también la imagen que recibe el intelecto; de allí que las representaciones de los objetos son llamadas copias, ya que ellas conservan la misma forma que ellos (Sobre los pensamientos 25).

Por ello indica que "Si las representaciones son el mal, aquel que ha fabricado el intelecto de una tal manera es responsable" (Capitulos de los discipulos de Evagrio 118), queriendo con esto decir que el intelecto conoce mediante vo $\mu \alpha \tau \alpha$ y que, por tanto, no está allí el mal pues así hemos sido creados por Dios. En este sentido, vemos que los vớ $\mu \alpha \tau \alpha$ no son necesariamente logismoí y lo que el monje debe cuidar es que no se transformen en logismoi sino que sean el medio para alcanzar un conocimiento profundo y verdadero de las cosas. Esto está expresado bellamente en el capítulo diecisiete del tratado Sobre los pensamientos, donde el Póntico, usando imágenes bíblicas, deja en claro que son las pasiones las que hacen a una representación un producto cognitivo, por así decir, mórbido, cuando ellas son en realidad el medio para conocer una realidad que le ha sido dada al hombre para ascender hacia el conocimiento de Dios.

El Señor ha confiado las representaciones de este siglo al hombre como ovejas a un buen pastor [...] Para ayudarlo, le ha dado la parte irascible y la parte concupiscible, a fin de que la primera ponga en fuga a las representaciones que son lobos, y por la segunda cuide a las ovejas. [...] Es necesario entonces, que el anacoreta vigile noche y día a este pequeño rebańo, por miedo a que alguna de las representaciones sea presa de las bestias salvajes o caiga en manos de malhechores, y si tal cosa sucede debe enseguida arrancarla de la boca del león y de la osa. La representación concerniente a un hermano deviene presa de las bestias salvajes, si se la hace pastar en nosotros con odio; la que concierne a la mujer, si se la alimenta en nosotros con una concupiscencia vergonzosa; la de la plata y el oro, si ella es acorralada con codicia; y las representaciones de los santos carismas, si se las hace pastar en compañía de la vanagloria. Lo mismo ocurrirá con otras representaciones, cuando ellas son la presa de las pasiones (17).

También en los Capitulos de los discípulos de Evagrio, se insiste repetidamente en esta idea: 
No es contra los objetos ni contra las representaciones, sino contra las pasiones que se les adjuntan que debemos combatir (65).

Si las representaciones de los objetos son el mal, aquel que ha fabricado el intelecto de una tal manera es responsable, y si los objetos fueran el mal, aquel que los ha creado sería él mismo responsable. Pero ni las representaciones ni los objetos son el mal, evidentemente, sino el movimiento del libre arbitrio hacia lo peor (118).

El mal no está en el intelecto, ni en el objeto, ni en la representación del objeto, sino en la pasión unida a la representación. Y soy yo quien es responsable de su existencia, ya que lo soy también de su desaparición (165).

Consignemos, por último, un texto más que repite la misma idea y que pertenece a los Escolios a los Salmos: "No son los objetos ni sus representaciones, sino las representaciones apasionadas de los objetos quienes encadenan el intelecto" (Escolio al versículo 7 del salmo 145).

Vemos entonces que las pasiones desorbitadas pueden instrumentar los voฑ́ $\mu \alpha \tau \alpha$ y transformarlos así en logismoí. Este es el sentido de decir que los logismoi son actividad cognitiva imaginativa propia de la enfermedad del alma.

Pero atendamos ahora al carácter racional-lógico (complementario del imaginativo) que también pueden tener los logismoí, y que vemos desplegado, de modo eminente, en Antirrhético. Ya hemos visto en aquel texto de Capitulos de los discípulos de Evagrio que citábamos más arriba, que los logismoí se caracterizan por

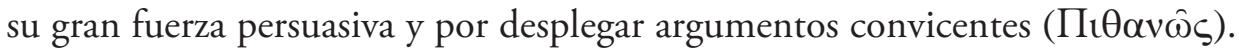
Pues bien, el Antirrhético es un ejemplo exhaustivo de cómo los logismoí son generalmente elaboraciones lógicas procedentes de las inclinaciones pasionales o de las disposiciones habituales de la parte pasional del alma enferma, que procuran mediante argumentos convincentes garantizar la satisfacción de esas pasiones a cuyo calor nacen. Digamos en este sentido que los logismoi constituyen una actividad racional al servicio de las pasiones. Consignemos a modo de ejemplo algunas sugestiones concretas de los ocho logismoí que podemos encontrar en la citada obra Antirrhético, para ver cómo Evagrio identifica la lógica pasional de los pensamientos malvados a fin de desbaratarla. Las sugestiones concretas son reconducidas a su raíz pasional dejando en evidencia el engaño de los argumentos que usan mediante la presentación de un texto de la Escritura opuesto. Ya en el prólogo mismo a esta obra nuestro autor nos habla de la necesidad de 
identificar la "insensatez" de estas sugestiones como primer paso para desarticularlas (Prólogo 3).

Comencemos por una sugestión del logismós de la avaricia que, aunque no explicita como otros pasajes, el razonamiento completo de la sugestión, sí contiene excepcionalmente una explicación muy clara de aquello que indicamos respecto a cómo Evagrio intenta reconducir a su raíz pasional al logismós a fin de desbaratarlo.

Para el alma que recibe oro destinado a la utilidad de los hermanos y, olvidando la lepra de Guejazí, desea gastarlo a su antojo -aquellos que leen reflexionen sobre cómo el profeta Eliseo había develado el pensamiento de avaricia, primero indicando las pasiones malvadas y, luego, los razonamientos que lo circundan; el resultado de ello es un largo período en el cual los pensamientos obstaculizan con intenciones malvadas la mente y la vuelven leprosa (Antirrhético III, 15) ${ }^{17}$.

En el caso de la gula, Evagrio identifica razonamientos engañosos como este:

Contra el pensamiento que nos impide compartir nuestra provisión de alimento y nuestros vestidos con los necesitados por el hecho de que los recursos no son suficientes para nosotros y para ellos; él [nos sugiere] que hay ciertamente otro más débil y necesitado que el que está delante y es a ese a quien conviene dar y no a éste, que busca comer y vestirse sin fatiga: 'Quien tiene dos túnicas, dé una a quien no tiene; y quien tiene alimento, haga otro tanto' (Lc. 3, 11). (Antirrhético I, 49)

En el caso de la soberbia, el Póntico identifica como procedente de la pasión por la autoexaltación, ciertos pensamientos y razonamientos acerca de sí y de los otros, e incluso ciertos juicios de tipo doctrinal erróneos. Identifica y reconduce a aquella pasión, por ejemplo, las siguientes autoevaluaciones:

El pensamiento de la soberbia que me exalta y me levanta en alto como uno que es irreprensible y no acoge más pensamientos impuros. (VIII, 2)

17 Evagrio se está refiriendo aquí a un pasaje del segundo libro de los Reyes (5, 17-27), en el cual el profeta Eliseo descubre el engaño de su siervo Guejazí que actúa movido por la avaricia. 
Contra el pensamiento soberbio que me glorifica, ya que, habiendo orado, no solo no soy más esclavo del vientre, sino que incluso he vencido a la ira. (VIII, 55)

El pensamiento de soberbia que me alaba porque yo he edificado las almas [conduciéndolas] sobre rectas sendas y [guiándolas] al conocimiento de Dios. (VIII, 30)

También despeja la raíz pasional de ciertos juicios y razonamientos acerca de los otros hombres:

El pensamiento [de la soberbia] que nos aconseja despreciar a nuestros santos padres porque no han sufrido tanto como nosotros en su vida. (VIII, 8)

El pensamiento de la soberbia que se burla de la soberbia de los hermanos por considerarlos negligentes en la práctica de los mandamientos. (VIII, 31)

El pensamiento soberbio que se justifica a sí mismo y no es benévolo hacia algo que ha sido hecho por los hermanos por debilidad. (VIII, 52)

El pensamiento soberbio que desprecia al hermano que no come y lo considera una persona débil que se da al ayuno porque, si comiese, no estaría en grado de combatir. (VIII, 55)

Asimismo es en la identificación de las sugestiones de la pasión de la soberbia, donde Evagrio aborda un tópico que también aparece en otras obras y que muestra claramente su noción -en el marco de la cual debe ser inscripta su concepción de los logismoí- acerca de la actividad racional que puede estar al servicio de las pasiones enfermas. Nos referimos a la raíz pasional que encuentra en la postu-

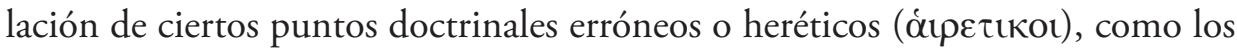
llaman los Capitulos de los discípulos de Evagrio. En Antirrhético reconduce, por ejemplo, a la soberbia el siguiente razonamiento de implicancia doctrinal: "El pensamiento blasfemo que niega nuestra libertad y dice que no es por nuestra voluntad que pecamos o somos justificados, por tanto el juicio no será pronunciado en manera justa” (VIII, 16). 
Por lo demás, la soberbia mueve principalmente a una concepción errónea de Dios que constituye para Evagrio "la caída más grave" (Tratado Práctico 14). Dios no es ya la causa de las buenas acciones $(I b$.) ni aquél de quien proviene la victoria (Antirrhético VIII, 22), sino que "el pensamiento soberbio se considera a sí mismo Dios" (Antirrhético VIII, 49b).

En otras obras se habla también de esta raíz pasional que tendría lo que

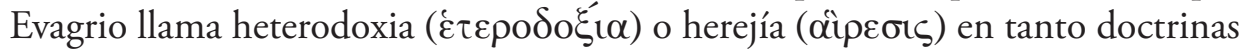
erróneas. Mencionemos esto -y consignemos algunos textos de muestra- como la expresión más radical de aquella actividad racional al servicio de las pasiones que tiene en los logismoí sus productos primarios y en las postulaciones doctrinales "heréticas" el corolario de la acción persistente y triunfante de éstos. En Kephálaia Gnóstica aparece, por ejemplo, la idea de cómo las pasiones oscurecen la visión de las razones de las disposiciones de Dios: "El movimiento multiforme y las pasiones diversas de los logikoi han forzado las intelecciones que conciernen a la providencia a aparecer oscuramente, y su índole diversa ha ocultado las intelecciones que conciernen al juicio" $(\mathrm{V}, 23)$.

En Escolios a los Proverbios, se pone de manifiesto lacónicamente el grado de extravío intelectual al que podría llegar el alma que no ha logrado dominio sobre su concupiscencia: "El alma pura encuentra sus delicias en la ciencia, pero el alma impura considera incluso la pseudociencia como la verdadera ciencia” (331).

En los Capitulos de los discípulos de Evagrio, la idea es expuesta con meridiana claridad comprendiendo la herejía como el resultado intelectual de una vida en la que no se ha combatido contra las pasiones:

Los heréticos son pues castigados, no porque ellos son heréticos, sino porque ellos han llevado una vida malvada, porque no es posible devenir herético si no se ha llevado una vida malvada, sea en palabra sea en acción. Ellos sufrirán pues un justo juicio, no porque ellos tropiecen sino porque, cegándose con la embriaguez, la desobediencia y la avaricia, ellos 'avanzan en la oscuridad' (125 cum supplemento [F3]).

En el mismo sentido, en su obra El gnóstico, nuestro autor previene insistentemente contra ciertas indagaciones y discusiones intelectuales prematuras -sobre todo de los jóvenes- en las que se buscan abordar -sin haber alcanzado una mesura mínima de las pasiones- aspectos doctrinales, o "escrutar" imprudentemente y sin orientación de un sabio "las razones de los corporales y de 
los incorpóreos" (25). En esta discusión prematura que está al servicio de las pasiones, de la "gloria pasajera" (El gnóstico 24), se halla el caldo de cultivo de los heréticos: "No es el mismo el tiempo de la explicación y el de la discusión. Es necesario reprimir a esos que prematuramente hacen objeciones. Está allí, en efecto, la costumbre de los heréticos y de los disputadores" (El gnóstico 26) ${ }^{18}$.

\section{EI rol de los demonios}

En este contexto no resulta extrańo que, al hablar de la finalidad que persiguen los demonios y por la cual entran a jugar un rol que aún no hemos explicitado en la conformación de los logismoí, Evagrio se refiera expresamente al alejamiento del conocimiento:

Acerca de la contemplación de los seres y de la ciencia de la Trinidad, los demonios y nosotros sostenemos un gran combate; ellos queriendo impedirnos conocer y nosotros buscando aprender (Kephálaia Gnostica III, 41).

Toda guerra que se libra entre nosotros y los demonios impuros, no tiene otro motivo que la contemplación espiritual; pues ésta es muy hostil y odiosa para ellos; mas para nosotros es causa de salvación y muy agradable (Sobre la oración 50 ).

Ya hemos indicado que Evagrio apela en diversas ocasiones a los demonios para explicar los logismoí. Dilucidar su acción nos permite tener una visión completa de todos los sentidos en que el término logismoi es usado por Evagrio y ver mejor hasta qué punto es por este producto cognitivo del alma enferma, que la condición mórbida misma se puede profundizar.

No podemos ignorar, si queremos ser fieles al pensamiento del Póntico, esta presencia preternatural que él percibe en la vida de los hombres y que se vuelve palmaria a su entender en el ámbito del pensamiento y de estos productos característicos del alma enferma que son los logismoi. Los demonios, en efecto,

18 Comentando la idea que Evagrio desarrolla en estos capítulos, Guillaumont y Géhin remiten al diálogo platónico República (VII, 539 ad). Efectivamente, encontramos en esta obra del discípulo de Sócrates, una idea semejante a la desarrollada por Evagrio en El gnóstico pues Platón se refiere allí a los peligros que entraña admitir prematuramente a los jóvenes en la dialéctica en tanto no tienen las disposiciones requeridas y ello no haría mas que aumentar en ellos el gusto reprobable por la disputa y el escepticismo. 
"como resultado del estudio, han aprendido el lenguaje de los hombres" (Kephálaia Gnóstica IV, 35) y es en el lenguaje interior del hombre donde concretan su ataque. Ellos soplan, dicen, sugieren palabras al oído, indica Evagrio ${ }^{19}$. El lenguaje posee en el pensador del Ponto un potencial patógeno cuyo negativo es su virtualidad curativa, como hemos intentado demostrar en otro lugar (Vazquez, 2017). Los demonios buscan, en efecto, profundizar la enfermedad.

Esta apelación a una realidad preternatural que Evagrio realiza con frecuencia al hablar de los logismoí, se complementa naturalmente en su pensamiento con una comprensión que podríamos denominar más estrictamente psicológica. Los demonios -que, como los ángeles, poseen, de acuerdo al pensamiento evagriano, una influencia concreta sobre la vida de los hombres ${ }^{20}$ - lo que hacen, en rigor, es reforzar mediante palabras el movimiento pasional propio del alma enferma. Imprimen representaciones y procuran reforzar la lógica de las pasiones. Por ello en ocasiones Evagrio identifica su influencia con los logismoí. Que estos sean, como hemos dicho, el correlato cognitivo de las pasiones enfermas sigue siendo válido pues, como decimos, lo que hacen los demonios, de acuerdo al pensamiento de Evagrio, es valerse del movimiento pasional parà phýsin y de su correlato cognitivo anejo para introducir hábilmente palabras e impresiones que profundicen ese movimiento y consoliden el pensamiento que de él surge. Por eso Evagrio indica que "Los demonios prevalecen sobre el alma cuando las pasiones se multiplican” (Kephálaia Gnóstica IV, 85). Cuando la parte irascible "está plena de humildad por el recuerdo de Dios", y la parte concupiscible "está toda inclinada hacia el Señor", entonces el nous "no teme a nuestros adversarios que circulan por fuera del cuerpo" (Kephálaia Gnóstica IV, 73): "De los (varios tipos de) pensamientos, algunos nacen de un movimiento del alma. Otros vienen de fuera, por las acciones de los demonios" (Skemmata 48).

Esta acción que viene de fuera por lo general se asocia a una pasión y sus sugestiones toman fuerza en el alma a partir de dicha pasión, pues se refieren a recuerdos, palabras, razonamientos vinculados a ésta:

A causa de la codicia los demonios hacen nacer [en el alma] todo género de tentaciones (Antirrhético II, 62).

19 Cfr. Antirrhético I, 2, 3, 17; II, 4, 5; III, 16, 37; V, 26; VI, 41, 4321.

20 "Los ángeles y los demonios se acercan a nuestro mundo; pero nosotros no podemos acercarnos a sus mundos. En efecto, no podemos hacer que los ángeles se aproximen más a Dios, ni pensar en contaminar más a los demonios" (Kephálaia Gnóstica III, 78). 
El demonio de la fornicación por medio de un deseo pasional imprime una visión de aspecto impuro en mi mente (Antirrhético II, 54).

Investiguemos cómo [los demonios] ponen en movimiento la memoria; ¿no será por intermedio de las pasiones? Sí, evidentemente (Sobre los pensamientos 4).

Cuando, habiendo cogido un pretexto, la parte irascible de nuestra alma es profundamente turbada, allí está el momento en el que los demonios nos sugieren que la anacoresis es bella, para impedirnos poner fin a lo que había causado nuestra tristeza, y liberarnos así de nuestra turbación. Pero cuando la parte concupiscible es violentamente excitada, entonces, al contrario, ellos trabajan para hacernos sociables, nos llaman duros y salvajes a fin de que, deseando cuerpos, tengamos comercio con cuerpos (Tratado Práctico 22).

La acción del demonio toma su fuerza de la enfermedad de las pasiones, pues "es a partir de estas dos pasiones (se refiere a las partes irascible y concupiscible) que se forman poco a poco todos los pensamientos demoníacos que precipitan el intelecto en la ruina y la perdición" (Sobre los pensamientos 3). Y por ello el Póntico dirá que "La impasibilidad imperfecta se dice en relación a la potencia del demonio que lucha aún contra ella [el alma]" (Tratado Práctico 60), queriendo significar con ello, como indica Guillaumont en el comentario a este pasaje, que la fuerza de los demonios viene de lo que le falta al alma para llegar a la salud de las pasiones o impasibilidad (apátheia). En el capítulo treinta y cuatro del tratado Sobre los pensamientos, nuestro autor indica que cada demonio tiene una "pasión que le es cara" y que son "los pensamientos de una cierta pasión" los que él acicala a fin de hacer implosionar y poner en movimiento esa pasión. Es decir, que los demonios, por así decir, se "especializan" en una pasión, reconocen las palabras y los pensamientos inherentes a ella y son capaces de promoverlos a fin de llevar al nous lejos del conocimiento y "apagar su bienaventurada luz" (Sobre los pensamientos 37) por la satisfacción de una pasión.

\section{Los logismoí y el hundimiento en la ignorancia}

Señala Peretó Rivas que "para Evagrio Póntico la ignorancia no es solo ausencia de conocimiento sino que es conocimiento de una realidad falsa, presentada como tal por los logismoi" (Peretó Rivas, 2014: 76). A esto puede estar haciendo referencia Evagrio cuando indica que el alma sumida en la ignorancia y en las 
pasiones que engendran los logismoí, ve fantasmas, es decir, ve cosas que no existen y que se interponen entre la realidad y ella: "El tercer renunciamiento es la separación de la ignorancia, la cual tiene la costumbre de aparecer a los hombres como fantasmas en el combate, según el grado de su crecimiento" (Kephálaia Gnóstica I, $\left.80\left[\mathrm{~S}_{1}\right]\right)$.

Interpretando alegóricamente la Sagrada Escritura, Evagrio dirá que los filisteos quieren ocupar la tierra prometida (Kephálaia Gnóstica V, 30). Ésta es en Evagrio el símbolo del conocimiento de la realidad creada (physiké), y aquéllos [los filisteos] el de los demonios. Que los filisteos quieran ocupar la tierra prometida sugiere que los demonios -que aquí son considerados en aquel rol de promotores de los logismoi - quieren usurpar el ámbito del conocimiento y proponer uno falso.

De este modo con estas consideraciones acerca de los logismoí desembocamos, como no puede ser de otra manera, en la ignorancia. En efecto, con su acción sobre el alma los logismoi - procedan o no de una sugestión demoníaca directano hacen sino -cuando sus insinuaciones tienen éxito- aumentar y profundizar la ignorancia: buscan llegar al extremo de considerar al propio ser como absolutamente independiente de Dios y, consecuentemente, como Dios mismo, según hemos visto. Se arriba así a una noción de sí específicamente opuesta a aquella que el nous poseía en el estado de unidad ( $\mu$ ov $\alpha \varsigma)$.

Recordemos que el logismós del orgullo busca "no reconocer que la victoria viene de Dios" (Antirrhético VIII, 22) sino que "atribuye la victoria a las propias fuerzas" (Antirrhético VIII, 25) e "incita a no reconocer la ayuda de Dios, sino a creer que es ella [el alma] misma la causa de las buenas acciones" (Tratado Práctico 14). El alma puede llegar al extremo en el que "se considera a sí misma Dios" (Antirrhético VIII, 49b).

No es extraño que Evagrio al referirse a esta suprema ignorancia de sí, hable también de enfermedad: "Está enfermo (voocî) de soberbia quien se separa de Dios, atribuyendo a las propias fuerzas las obras rectas que cumple" (Ocho espiritus de la maldad 17).

Por ello con este descenso a la suprema ignorancia que pueden operar los logismoí, se arriba a la "caída más grave" (Tratado Práctico 14) y a una especie de paroxismo: "Vienen a continuación la cólera, la tristeza y, lo que es el último de los males, el extravío del espíritu, la visión de una muchedumbre de demonios 
en el aire" (Ib.). Así, y como indica nuestro autor en Escolios al Eclesiastés, si se

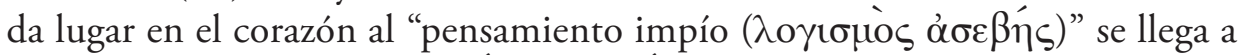

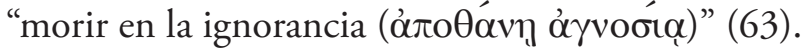

Un ejemplo gráfico de este hundimiento mortal en la ignorancia suprema que es el orgullo, se puede encontrar en la historia del anciano Herón relatada por el discípulo de Evagrio, Casiano, en una de sus Conferencias y evocada por Evagrio al hablar precisamente del orgullo. Este logismós puede, en la compresión evagriana del dinamismo psicoespiritual, enfermar al monje y enloquecerlo hasta el punto de pensar, por ej., que por el mérito de sus virtudes y trabajos, por haber llegado a ser un "monje perfecto" (Antirrhético VIII, 39), podría salir indemne después de precipitarse a un pozo, como relata Casiano que le sucedió al anciano Herón (Conferencias II, 5, 1-4). Resulta significativo el texto de la Sagrada Escritura que, sin más, evoca Evagrio para rechazar el logismós que engaña al monje susurrándole al oído que ha logrado la perfección. Se trata del fragmento del Eclesiastés que reza: "Es mejor un perro vivo que un león muerto" (Antirrhético VIII, 39). Nuestro monje podría estar recordando aquí al anciano Herón. En efecto, en el capítulo veintitrés de su tratado Sobre los pensamientos y en el diecisiete de su obra Ocho espiritus de la maldad, realiza una descripción detallada del desequilibrio psíquico y el hundimiento final en la locura en que se puede caer a causa de los pensamientos de orgullo y hace referencia, en el primero de los tratados, a dos hermanos suyos en la vida monástica cuyo naufragio mental está siempre aleccionadoramente bajo sus ojos. Guillaumont y Géhin señalan, comentando este pasaje, que muy probablemente Evagrio está haciendo referencia aquí a dos monjes de los que habla el discípulo y biógrafo de monje del Ponto, Paladio, en su Historia Lausiaca (Géhin, Guillaumont, C. y Guillaumont, A., 1998: 234). Estos dos monjes son Valens y Herón. Por lo demás, Casiano es contemporáneo y discípulo de Evagrio y es este último una de sus principales fuentes (Cfr. Pichery, 2008: 65).

Aquel orgullo o soberbia desequilibrante -fundada en la necesidad de enaltecer y exaltar al propio yo- es la que lleva al monje a creer que ha alcanzado la perfección, que ha subido hasta una gran altura, que él es la causa de muchas buenas acciones y que el resto le debe reconocimiento por ello (Cfr. Tratado Práctico 14; Ocho espiritus de la maldad 17). Aquella necesidad de exaltar al yo que lleva a imaginar y a proyectar determinadas situaciones en las que el propio yo es enaltecido y alabado (Cfr. Tratado Práctico 13), deviene en una creencia irracional consistente en la certeza de que se ha alcanzado por las solas fuerzas la perfección. 
Alcanzado este endiosamiento se está, por lo mismo, incluso más allá de las leyes de la naturaleza. Tirarse a un pozo y salir indemne lo probaría. Aquella condición irremediable y definitiva que Evagrio ve en el naufragio del orgullo, se muestra patentemente en el caso de Herón el cual persiste en su delirio de grandeza, aún moribundo durante los dos días que duró su agonía (Conferencias II, 5, 4). Por eso Evagrio propone frente al pensamiento "que me exalta como si hubiera alcanzado la perfección en la práctica de los mandamientos" (Antirrhético VIII, 58) o "como si en mi mente no hubiera huella de pecado" (Antirrhético VIII, 59), la meditación de textos de la Escritura que muestren el engaño demoníaco que significa creerse perfecto y sin huella de pecado. Propone comprender adecuadamente el yo a la luz de las Sagradas Escrituras.

\section{Conclusiones}

Hemos podido verificar a lo largo de nuestro desarrollo que los logismoi son el correlato cognitivo de la actividad pasional enferma y, más ampliamente, la manifestación al nivel del pensamiento de la enfermedad del alma. En efecto, pudimos identificar y diferenciar las distintas realidades que Evagrio designa con el término concluyendo, en todos los casos, que estamos frente a la traducción cognitiva de las pasiones enfermas. Logismoi son tanto representaciones apasionadas, cuanto actividad lógica al servicio de los deseos parà phýsin de las partes concupiscible e irascible del alma. Asimismo el modo en el que Evagrio presenta el posible rol de los demonios en el desarrollo de esta actividad representacional o lógica, no pone de manifiesto una posible vacilación de nuestro autor entre una explicación psicológica y otra religiosa del estado del alma enferma. Por el contrario, hemos podido observar que esta apelación a una realidad preternatural que Evagrio realiza con frecuencia al hablar de los logismoí, se complementa naturalmente en su pensamiento con una comprensión que podríamos denominar más estrictamente psicológica. Lo que hacen los demonios es valerse del movimiento pasional parà phýsin y de su correlato cognitivo anejo para introducir hábilmente palabras, impresiones o recuerdos que profundicen ese movimiento y consoliden el pensamiento que de él surge.

Los logismoí son así el último eslabón de la cadena de causas y consecuencias de la enfermedad del alma. Vimos que ellos profundizan aquella ignorancia que está en el origen de todo el dinamismo "patológico" con el que Evagrio entiende el estado postlapsario del alma. Ellos, profundizando el movimiento pasional parà phýsin, oscurecen aún más la inteligencia impidiéndole abrirse al conocimiento 
de las cosas y de sí mismo. La caída más grave que ellos propician es precisamente la de llegar a una noción de sí y de Dios específicamente distinta a aquella del estado de unidad al que el alma está vocada, allí donde se halla la " $\mu$ ovó $\delta \delta$ os íyźi (salud de la unidad)" (Capitulos de los discípulos de Evagrio 8).

\section{Referencias}

Alby, J. C. (2011). La asthéneia en la antropología cristiana primitiva", en: Scripta Mediaevalia, 4:1, pp. 11-26.

Bunge, G. (1989). "Notas", en: Pontikos, Evagrios (1989). Praktikos oder der Mönch, Köln: Luthe-Verlag.

Casiano, J. (2008). Conférences I-VII, traducción y notas Dom Eugène Pichery, Paris: Cerf.

Daniélou, J. (1957). "Démon", en: Dictionnaire de Spiritualité, vol. 3, Paris: Beauchesne, p. 187.

Forthomme, B. (2000). De l'acédie monastique à l'anxio-depression. Histoire philosophique de la transformation d'un vice en pathologie, París: Synthélabo.

GÉHIN, P. (2007). "Introduction”, en: Póntico, Evagrio (2007). Chapitres des disciples d'Évagre (pp. 19-98), introducción, traducción y comentarios de P. Géhin, Paris: Cerf.

Géhin, P; Guillaumont, C. \& Guillaumont, A. (1998). "Introduction", en: Póntico, Evagrio (1998). Sur les pensées (pp. 9-136), Paris: Cerf.

- (1998). "Notas", en: Póntico, Evagrio, Sur les pensées, Paris: Cerf.

Guillaumont, A. (2009). Un philosophe au désert. Evagre le Pontique. Paris: Vrin.

Kalvesmaki, J (ed. 2017). Guide to Evagrius Ponticus, spring 2017 edition, Washington, DC: http://evagriusponticus.net/corpus.htm;

Konstantinovsky, J. (2009). Evagrius Ponticus. The Making of a Gnostic. Farnham: Ashgate.

LARChEt, J.-C. (2007). "Recension: 'Chapitres des disciples d'Évagre”, en: http:// orthodoxie.com/recension-chapi/

Paramelle, J. (1978). "Chapitres des disciples d'Évagre dans un manuscrit grec du musée Bénaki d'Athènes", Parole de l'Orient: revue semestrielle des études syriaques et arabes chrétiennes vol. 6-7, pp. 101-113.

Peretó Rivas, R. (2011). "Las mutaciones de la acedia. De la Patrística a la Edad Media”, Studium. Filosofía y Teología 27, pp. 157-171. 
- (2014). "Conocimiento e ignorancia en Evagrio Póntico", Cauriensia IX, pp. 75-93.

Pesthy, M. (2003). “Logismoí Origéniens - Logismoí Évagriens”, en: Perrone, L., Bernardino, P. \& Marchini, D. (eds.), Origeniana Octava, Leuven, Leuven University Press / Peeters, pp. 1017-1022.

Pichery, D. E. (2008). “Introduction”, en: Casiano, J. (2008) Conférences (I-VII) (pp. 7-78), introducción, traducción y notas de Dom Eugène Pichery, SC 42 bis, Paris: Cerf.

Póntico, Evagrio (1971). Traité Pratique ou le moine. Introducción, traducción y notas de Antoine Guillaumont y Claire Guillaumont, Sources Chrétiennes 171, Paris: Cerf.

- (1985). Les six centuries des 'Kephalaia gnostica' d'Évagre le Pontique, traducción de Antoine Guillaumont, Patrologia Orientalis T. XXVIII, fascicule 1, Paris: Brepols.

- (1987). Scholies aux Proverbes, introducción, traducción y notas de Paul Géhin, Sources Chrétiennes 340, Paris: Cerf.

- (1989/2008). Le gnostique ou a celui qui est devenu digne de la science, introducción, traducción y notas de Antoine Guillaumont y Claire Guillaumont, Sources Chrétiennes 356, Paris: Cerf.

- (1993). Scholies à l'Ecclésiaste, introducción, traducción y notas de Paul Géhin, Sources Chrétiennes 397, Paris: Cerf.

- (1995). A los monjes, en: Obras espirituales (pp. 177-211), introducción, traducción y notas de José I. González Villanueva y Juan Pablo Rubio Sadia, Madrid: Ciudad Nueva.

- (1995). Sobre la Oración, en: Obras espirituales (pp. 229-275), introducción, traducción y notas de José I. González Villanueva y Juan Pablo Rubio Sadia, Madrid: Ciudad Nueva.

- (1996). Gli otto spiriti della malvagità, introducción, traducción y notas de Francesca Moscatelli, Milano: San Paolo.

- (1998). Sur les pensées, introducción, traducción y notas de Paul Géhin, Claire Guillaumont y Antoine Guillaumont, Sources Chrétiennes 438, Paris: Cerf.

- (2001). Skemmata, introducción, traducción y notas de William Harmless y And Raymond R. Fitzgerald. En: "The sapphire light of the mind: the Skemmata of Evagrius Ponticus", Theological Studies, 62, pp. 498-529.

- (2005). Contro i pensieri malvagi. Antirrhetikos, introducción de Gabriel Bunge, traducción y notas de Valerio Lazzeri, Magnano: Qiqajon.

- (2007). Chapitres des disciples d'Évagre, introducción, traducción y notas de Paul Géhin, Sources Chrétiennes 514, Paris: Cerf. 
- (2015). Evagrius's Kephalaia Gnostica: A New Translation of the Unreformed Text from the Syriac, introducción, traducción y notas de Illaria Ramelli, Writings from the Greco-Roman World, Atlanta: SBL Press.

- (En línea). Carta 55, en: L. Dysinger, "St. Evagrius Ponticus (345-399). Selected Letters”, Monastic Spirituality Self-Study (Website), 1990: http://www.ldysinger. com/Evagrius/11_Letters/00a_start.htm

- (En línea). Escolios a los salmos, en: L. Dysinger, "St. Evagrius Ponticus (345-399). Selected Letters", Monastic Spirituality Self-Study (Website), 1990: http://www. ldysinger.com/Evagrius/08_Psalms/00a_start.htm

TовоN, M. (2011). "Evagrius as Writer: The Example of Eulogios 2's Discussion of Xeniteia", en: Kaczmarek, S., Dziadowiec, A. \& Pietras, H. (eds.), Origeniana decima: Origen as writer: papers of the 10th International Origen Congress, University School of Philosophy and Education Ignatianum (pp. 765-778), Krakow, Poland, 31 August - 4 September 2009, Leuven: Peeters.

- (2010). Apatheia in the Teachings of Evagrius Ponticus, Th. D., London: University College.

VAZQUEZ, S. (2017). "La palabra y su dimensión terapéutica frente a la enfermedad del alma en Evagrio Póntico", Rivista di Storia e Letteratura Religiosa LIII/1, pp. 3-31.

- (2018). "La enfermedad del alma en el filósofo tardoantiguo Evagrio Póntico: entre ignorancia y filautía", Anales del seminario de historia de la filosofía 35/2, pp. 323343.

Recibido: 15/03/2018

Aceptado: 20/02/2019

Este trabajo se encuentra bajo una licencia de Creative Commons ReconocimientoNoComercial-SinObraDerivada 4.0

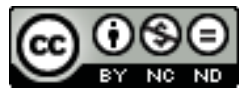

